\title{
MANAGERIAL CHALLENGES OF TEACHING HOSPITAL, A REVIEW OF THE EXISTING LITERATURE
}

\author{
Samaneh Safarani ${ }^{1}$, Pouran Raeissi ${ }^{2}$, Hamid Ravaghi ${ }^{3}$, Mohammadreza Maleki ${ }^{4}$
}

1Ph.D. candidate of Healthcare Services Administration, Department of Health Services Management, School of Health Management and Information Sciences, Iran University of Medical Sciences, Tehran, Iran.

2Professor, Department of Health Services Management, School of Health Management and Information Sciences, Iran University of Medical Sciences, Tehran, Iran.

${ }^{3}$ Associate Professor, Department of Health Services Management, School of Health Management and Information Sciences, Iran University of Medical Sciences, Tehran, Iran.

${ }^{4}$ Professor, Department of Health Services Management, School of Health Management and Information Sciences, Iran University of Medical Sciences, Tehran, Iran.

\begin{tabular}{l}
\hline ABSTRACT \\
\hline BACKGROUND \\
Teaching hospitals have three goals including curing, education and research. Providing education along with health care services \\
expands the mission and accountability of these goals and results in more challenges for managerial team of teaching hospitals in \\
comparison with non-teaching hospitals. Therefore, this research aims to review the existing literature regarding the challenges \\
that teaching hospital managers are facing with focus on different dimensions related to their functions.
\end{tabular}

\section{MATERIALS AND METHODS}

A comprehensive review was performed by searching the existing literature. We used different search strategies including electronic databases, reference checking and experts contact. The key words were combinations of the terms teaching hospitals or university hospitals and managerial/management problems and challenges. 56 studies were included according to predefined inclusion and exclusion criteria.

\section{RESULTS}

A range of managerial problems have been addressed in the existing literature. The most followed is planning among the problems of managerial dimensions (34\%), and then coordination (25\%), control and evaluation (16\%), leadership (12\%), organizing and organizational structure (10\%), and ultimately creativity, innovation and change dimension (3\%).

\section{CONCLUSION}

Also, the mentioned problems in teaching hospitals have different priority but for a complete and correct management to receive all three goals of a teaching hospital, managers should pay attention to all of these dimensions simultaneously. Better identification of these problems facilitates solving these managerial challenges more efficiently.

\section{KEY WORDS}

Managerial Challenges, Teaching or Academic Hospitals, Review Study.

HOW TO CITE THIS ARTICLE: Safarani S, Raeissi P, Ravaghi H, et al. Managerial challenges of teaching hospital, a review of the existing literature. J. Evolution Med. Dent. Sci. 2018;7(43):4686-4692, DOI: 10.14260/jemds/2018/1045

\section{BACKGROUND}

Health sector is considered as one of the most important service sectors.(1) In this regard, hospitals are one of the most important institutions in providing health services, (2) have a special role in the efficiency of the health system.(3) They, as the main pillar of each country's health system, are divided into two groups of teaching and nonteaching hospitals. (4) Teaching hospitals cover an important part of education and research in the field of health, and lead to the empowerment and educating of specialists in different disciplines. $(5,6)$ They, in most countries, are either affiliated with the medical school in terms of organizational structure or part of a national or

'Financial or Other Competing Interest': None.

Submission 15-09-2018, Peer Review 09-10-2018,

Acceptance 15-10-2018, Published 22-10-2018.

Corresponding Author:

Pouran Raeissi,

Professor, Department of Health Services Management, School of Health Management and Information Sciences, Iran University of

Medical Sciences, Tehran, Iran.

E-mail: raeissi2009@yahoo.com

DOI: $10.14260 /$ jemds/2018/1045 regional health system.(7) Today, hospitals use huge amounts of human, physical, financial, and equipment resources to provide, maintain, and promote the health of the community.(2) Given that teaching hospitals have three simultaneous roles including, educating different health professionals, providing health care, and research that make the managing of teaching hospital more important and difficult to balance among these tree functions such as providing quality and safety of health care services. $(8,9)$ Furthermore, the poor performance of teaching hospitals in the incidence of medical errors is often related to presence of medical students and educational nature of the teaching hospitals(10) and some patient complaints from mismanagement.(11) Also teaching hospitals in almost all developing countries receive a large amount of financial resources they are still looking for more resources.(12) The capacity of teaching hospital managers is an important issue and most of the directors and physicians may experience difficulties in balancing between managerial and academic roles.(13) Teaching hospitals need more comprehensive documentation and evidence-based decision making due to legal sensitivities, student education, and more supervision (In terms of responsiveness and evaluation).(14) 
Considering the simultaneous and multi-functional role of teaching hospitals, the efficacy of these hospitals is a major challenge for decision-makers in the health sector. The findings of related studies in different countries confirm that hospitals face different challenges in achieving their missions since some of them are self-regulated on one hand, and are responsible for providing health care to indigent people on the other hand. Accordingly, it seems necessary to take advantage of efficient management to overcome such complex issues, threatening the survival of teaching hospitals.[13,14] The results of some studies comparing teaching hospitals with non-teaching hospitals in developed countries showed that only $10 \%$ of the hospitals could effectively provide health care services tailored to patients.[15] There are some problems such as the lack of therapeutic and educational spaces, which sometimes result in problems concerning provision of health care services.[16,17] According to the predefined content, there are a wide range of hospital challenges. Many of these problems are related to the management functions and structure. Meanwhile, hospital management follows the basic principles of management like any other organization. The managerial team in teaching hospitals has 5 functions including planning, organizing, coordinating, leading, and controlling. In each of these major managerial duties of teaching hospitals, there are challenges such as weaknesses in internal and external coordination, the assignment of responsibilities, and the responsiveness of individuals, stakeholders, organizations and hotel ling quality.(18,19) Also, there were many previous studies which each of them partially mentioned to teaching hospitals challenges but there were no a holistic and review study that provide all teaching hospitals challenges together and with managerial functions approach. The novelty of present study is that it identified managerial challenges in teaching through review the existing literature and classified the challenges tasks according to 5 hospital management tasks that were not published before and also provided another category of management task as number6 with their challenges. Secondly, due to multi functions of teaching hospitals that make their managing more difficult, this study was attempted to provide a basis study for policymaking and planners in this area to learn of them and enhance the efficiency of managing teaching hospitals.

\section{MATERIALS AND METHODS}

In order to identify studies on the managerial challenges of teaching hospitals in different countries, we applied a comprehensive traditional review study of the existing articles and documents.

\section{Data Source}

The related contents were extracted, and their results were categorized and analysed by subject. The data were collected through electronic databases, reference checking and experts contact. Electronic databases, including Web of Science, Emerald, PubMed, and Scopus were searched. To collect studies performed in Iran, Irandoc, Magiran, SID, and other available documents were searched.

\section{Our Search Strategies}

The Search strategy was used included (Teaching Hospital and Challenges) or University Hospitals or "Academic Medical Centres") and (Management or "Manage* Challenge's") or (Problems*): ("Teaching Hospitals" or " University Hospitals") and ("Manage* challenges")

\section{Studies Selection Process and Criteria's}

In order to identify studies on the managerial challenges of teaching hospitals in different countries, we applied a comprehensive review of the existing articles and documents. The authors evaluated the most relevant studies through reviewing the title and abstract of them. Finally, relevant documents were then read in full text. Included articles were those related with the subject of hospital challenges of teaching hospitals. Excluded articles were those published prior to 2006, We used Studies that were conducted over the past ten years between 2006-2018 (to find both new and old documents) and published in English or Persian. We exclude those that were not related to our research question. Moreover, the articles were excluded if their full text was not available.

\section{Data Analysis}

To analyse data on the purpose, study design, country, and managerial challenges, descriptive statistics were applied. However, data on findings of studies about managerial challenges of teaching hospitals were analysed using content analysis.

\section{RESULTS}

Results based on functions of management were extracted. The search results that equivalents associated with teaching hospitals include "Academic Medical Centers", "University Hospitals", and "University Medical Centers"; and with management include "Hospital Chief Executive" and "Officers". In general, we found 77648 articles, then by applying time bounding, existing full articles and language bounding we had 1850 ones, after comprehensive search, all articles were viewed by title, the abstract and the full text and finally 56 studies were selected with respect to inclusion and exclusion criteria. Quality assessment of the articles was independently performed by 2 reviewers. The process of selecting studies was as follows (Figure 1). 


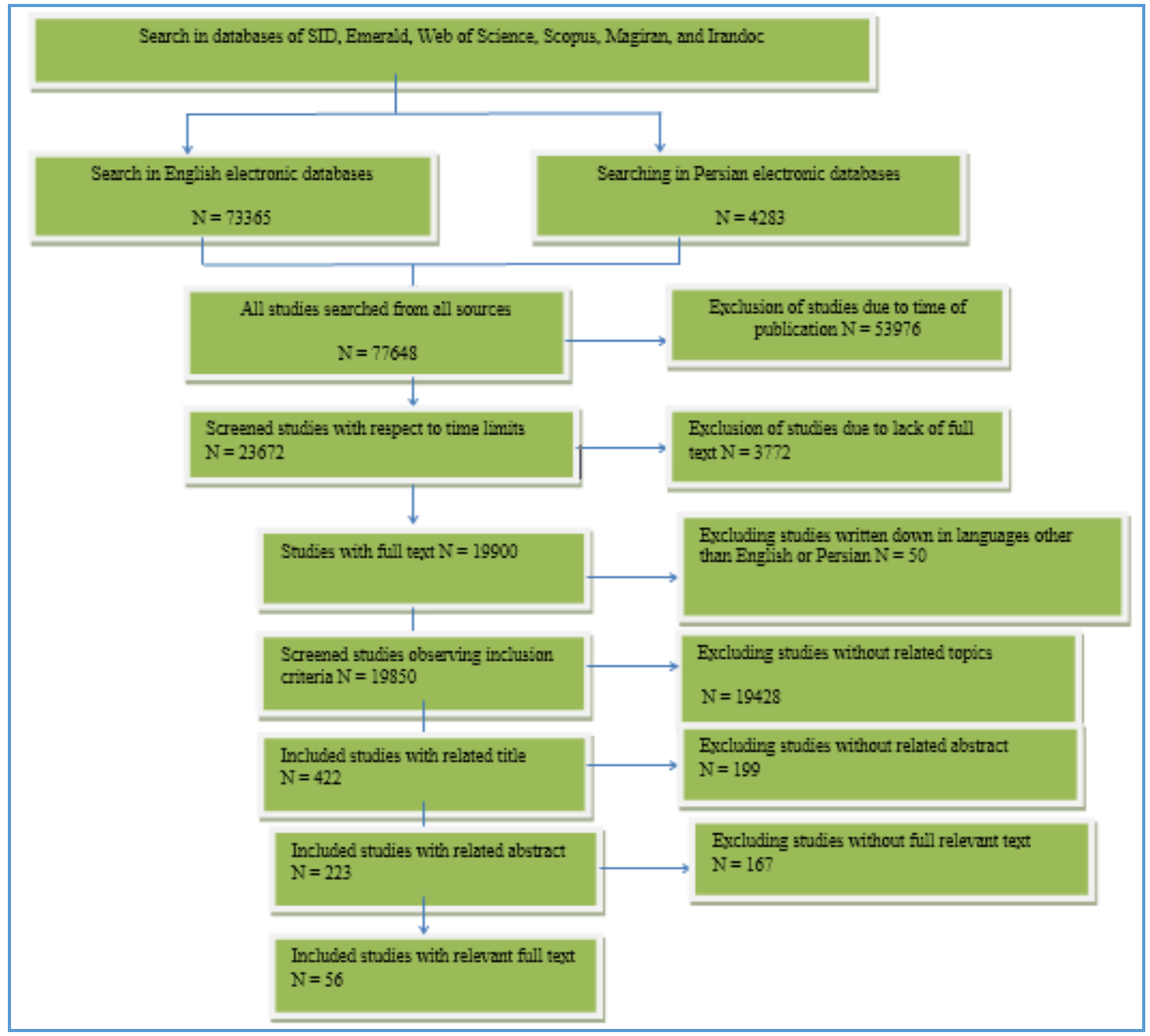

Figure 1. The process of selecting articles for a comprehensive overview.

Descriptive analysing of findings shows that the highest frequency concerning the type of the documents was allocated to articles and research reports (88\%), followed by books and thesis with (12\%) frequency. In other words, $86 \%$ of the searched documents were in form of a paper (including original research papers, review article, etc.), $2 \%$ were in the form of official reports, and $12 \%$ were thesis. Regarding the time of publication, 42\% were published from 2006 to 2011 and 58\% from 2012 to 2017 . With respect to design of the selected studies, $37.5 \%$ were quantitative, $33.92 \%$ were qualitative, and $28.57 \%$ used mixed method. The key findings and subject analysing of findings on the problems of managerial dimensions are presented in Table 1 . Table 2 illustrates the percentage of observed managerial problems.

\begin{tabular}{|l|c|}
\hline Managerial Dimensions & Key Findings (Challenges of Managerial Dimensions) \\
\hline 1. Planning & $\begin{array}{c}\text { Teaching Hospitals have weak strategic and operational planning to provide student facilities } \\
\text { and equipment in hospitals, insufficient budget and resources including human workforces } \\
\text { and equipment, low appropriate conditions for clinical education, scheduling the presence of } \\
\text { doctors and unbalanced planning in three goals of a teaching hospital }\end{array}$ \\
\hline 2. Organization & $\begin{array}{c}\text { Managers in Teaching Hospitals face lack of authority in internal organization and organizing } \\
\text { medical staff. They have no structure in Some duties such as researching. Manager's authority } \\
\text { is not balanced according to their responsibilities- }\end{array}$ \\
\hline $\begin{array}{l}\text { 3. Coordination } \\
\text { 4. Leadership }\end{array}$ & $\begin{array}{c}\text { There are low coordination between university student's number and their facilities to educate } \\
\text { including professor numbers, classrooms and residency places. Also, they have week external } \\
\text { coordination with other organizations. Internal coordination and communication is week too. } \\
\text { Coordination between educational, research and therapeutic tasks/duties is not sufficient. }\end{array}$ \\
\hline \multicolumn{2}{|c|}{$\begin{array}{c}\text { Leadership is also another managerial dimension which is not appropriate to the } \\
\text { organization's maturity, there is low guidance for university students, there is not enough } \\
\text { supervision and leadership accordingly rewards mechanism for staffs to reach the triple goals. }\end{array}$} \\
$\begin{array}{c}\text { 5. Evaluating } \\
\text { Teaching Hospitals have Problems in Controlling purposes and mission, internal and external } \\
\text { control, Evaluation and control according to objectives and with consideration of triple goals. } \\
\text { There are low continuous monitoring and evaluating. }\end{array}$ \\
\hline $\begin{array}{c}\text { 6. Other dimensions (creativity, } \\
\text { innovation, and change) }\end{array}$ & $\begin{array}{c}\text { There are problems in innovation and change in line with triple objectives; inflexibility in } \\
\text { management and leadership, there is no creativity and innovation in work places. }\end{array}$ \\
\hline \multicolumn{2}{|c|}{ Table 1. Key findings revealed by the selected studies and dividing challenges in managerial dimensions (12-70) }
\end{tabular}




\begin{tabular}{|c|c|c|c|}
\hline $\begin{array}{l}\text { Managerial } \\
\text { Dimensions }\end{array}$ & Frequency & Percentage & Priority \\
\hline Planning & 41 & $34 \%$ & 1 \\
\hline Organizing & 12 & $10 \%$ & 5 \\
\hline Coordination & 31 & $25 \%$ & 2 \\
\hline Leadership & 15 & $12 \%$ & 4 \\
\hline Control (evaluating) & 20 & $16 \%$ & 3 \\
\hline $\begin{array}{c}\text { Other dimensions } \\
\text { (creativity, innovation, } \\
\text { and change) }\end{array}$ & 3 & $3 \%$ & 6 \\
\hline Total & 122 & $100 \%$ & - \\
\hline
\end{tabular}

Findings of the research show that most of the management problems raised in the teaching hospitals, that is about $34 \%$ of them, are related to the planning dimension. These planning problems are divided into different dimensions: 5 cases are related to lack of funding and budget to promote teaching hospitals, 4 problems are about proper curriculum planning by the faculty members regardless of hospital facilities, 7 problems are attributed to students, managers, and staffs' curriculum weakness, 5 cases are due to lack of sufficient facilities and equipment to provide services in all three areas.

The most important next problem in the management dimension is coordination with a frequency of $25 \%$. Coordination includes weak internal and external relationships and other issues, which are as follows in the order of importance: 7 cases of weak communications with high organizations such as universities and medical faculties, 6 inadequate internal communications and interactions, 8 poor external coordination and communications with equal organizations, 5 problematic issues among educational and therapeutic goals, and 2 cases regarding lack of coordination between academic and clinical roles of faculty members.

The next managerial problem is the control and evaluation dimension, which accounts for $16 \%$ of the problems and includes defects in external and internal evaluation, inappropriate assessment with goals, lack of adequate parallel control of triple goals in the training hospitals, and 6 cases of inadequate clinical observation, monitoring, control, and evaluation of faculty members on the manner of education. Further, the impossibility of evaluating the multiple roles of faculty members, 2 cases of lack of adequate supervision on education and treatment.

The problem with the fourth priority is leadership and guidance in training hospitals with a score of $12 \%$, which includes the problems of non-flexibility in the way of leading different groups, that is directing imperative and magisterial, and guidance is non-cooperative. In addition, other problems include lack of adequate leadership and guidance of faculty members on students and educational groups, lack of clinical leadership, and also lack of leadership role among managers, failure to meet the triple goals in hospitals.

The problem with the fifth priority is related to organizing and organizational structure with $10 \%$ frequency. Such problems consist of failure to delegate sufficient authority from high organizations, lack of proper structure in the field of research and education and focused organizational structure in decision makings, inappropriate service delivery, or non-assignments that lead to waste of resources and high labor.
Finally, the last problem is related to another dimension that is added here; the creativity, innovation, and change dimension, with a score of $3 \%$, which was not among the mentioned five dimensions. It includes impossibility of change in the management of teaching hospitals and the impossibility of providing creativity in the triple goals of education, research, and treatment that are essential for improving the quality of services and lead to continuous improvement and development.

\section{DISCUSSION}

Although we have found these priority problems, these may not be the most important ones and in fact they show the most visible challenges such as budgeting, low facilities and so on that are in planning category but we cannot see the coordination challenges directly. Hospital management needs new, flexible, and creative methods in a constantly changing dynamic environment and policy makers and future managers should pay special care and attention to this matter.

About planning dimension, in findings of other studies, Mohseni (43) and Souba( ${ }^{62)}$ stated that there was a weakness among strategic planning, organizing, leadership of executive directors, and finally the performance of teaching hospitals. The weaknesses in each part of the function can affect other parts and impose a negative impact on overall performance of the hospital. Given the current status of accountability in hospitals' performance and its importance, strengthening the dimensions of weaknesses and addressing deficiencies in performance should be a priority for managers.

In the control dimension, findings of other studies states that there are concerning in the evaluation systems in teaching hospitals, Taslimi et al., showed that designing a performance appraisal system is essential, especially in teaching hospitals that are established with several purposes and tasks.(44) The findings of a study by Aljuaid et al. (2015) also indicated that due to the close relation between the medical schools and the medical care centers and necessity of their integration, a dominant and independent organization is required in to study the health services and tries to make more progress. Furthermore, a comprehensive system is needed for continuous quality assessment of the academic hospitals' achievement of goals within the university.(56)

Tess et al. (2015) conducted concluded that integration of the quality and safety missions among medical graduates and teaching hospitals is a necessary step.(27) This is consistent with the results reported by Hackman et al. (2014), regarding the problems associated with the attendance of students in teaching hospitals, Generally, the results showed that the medical residents' job rotations in medical hospitals reduce the medical efficiency by increasing the efficiency in resources.(58) The results reported by Kane(67) represented less productivity in teaching hospitals, which is consistent with the above mentioned results.

The studies by Valizadeh et al. (2007) and Oscovy et al. (2015), on educational planning showed that the clinical environment is not implemented properly for nursing students. Although the hospital is educational, educational facilities are not prepared and planned for training these students. So, it is necessary for the custodians in educationaltreatment centers to anticipate these preparations to facilitate the clinical environment for the education of 
students.(42) For this reason, medical schools and health care centers should have close contact and be integrated. Through methodologies such as coding programs together and with strategic collaboration, these problems will be resolved in the near future.(49)

But the studies in this regard are controversial. In the research conducted at Harvard University by John Ayanian the results indicated that the best hospitals from the viewpoints of physicians and academic figures are teaching hospitals, since they include high quality treatment, treatment of rare and complicated diseases, and provision of special services, advanced technology, and guidance of biological research.(68) Other specific duties of the teaching hospitals are healthcare training, inventions in medicine and nursing, and curing of the poor especially in public hospitals.(62) The mentioned study illustrates positive points of the teaching hospitals and its findings are consistent with those of Mirmoghtadai and colleagues in 2014. They announced that integration of medical education with health and treatment fields leads to positive development of expert human resources and the improvement of health indicators. ${ }^{(70)}$

\section{CONCLUSION}

Generally, the overall results of the existing studies regarding the challenges and problems of teaching hospitals indicate that despite many advances made in the last ten years, concerns still exist about the teaching hospitals. Considering the results, priority should be given to planning, coordination, control, leadership, organizing, creativity, and innovation. Better identification of these problems facilitates in removing these challenges and improves the performance and productivity of managerial functions in all aspects of education, research, and treatment in teaching hospitals.

\section{ACKNOWLEDGMENT}

This manuscript was a part of the doctoral dissertation approved by the Faculty of Management and Medical Information, Iran University of Medical Sciences with the ethics code of IUMS/SHMIS/1395/9321532002.

\section{REFERENCES}

[1] Karimi S, Nejadlabbaf S, Nasiri T, et al. Estimate of production function in selected public hospitals of Isfahan University of medical sciences. Health Inf Management 2013;10(4):557. [In Persian]

[2] Grifin D, Arab M, Valli L, et al. What is hospital and how it works? Iranian Student Book Agency. SID Publication 2015. [In Persian]

[3] Mahani SA, Goodarzi R, Barouni M, et al. Estimation of technical efficiency of general hospitals of Kerman university of medical sciences by Data Envelopment Analysis (DEA) method in 2007. Journal of Kerman University of Medical Sciences 2010;16(1):59-67.

[4] Ardalani M, Ardalani H. Hospital designing. 2015. [updated 2015 Feb 13; cited 2017 Jan 14]. http://hospital-ir.com/articledetails/6086 [In Persian]

[5] Kupersmith J. Quality of care in teaching hospitals: a literature review. Academic Medicine 2005;80(5):45866.
[6] American Hospital Aassociation. Teaching hospitals: Their impact on patients and the future health care workforce. Washington (USA): Association of American Medical Colleges. 2009 Sep, 8 p. [ Report No.: 202.638.1100] [Washington, DC 200042802202.638.1100]

[7] Browne E. Teaching hospitals. Islamic Medicine 2002. [updated 2017 Jan 17; cited 2016 Aug 29 16]. http://www.theinfolist.com/php/SummaryGet.php?Fi ndGo=List of university hospitals.

[8] Knapp RM. Quality and safety performance in teaching hospitals. The American Surgeon 2006;72(11):1051-4.

[9] Padmore JS, Jaeger J, Riesenberg LA, et al. "Renters" or "owners"? Residents' perceptions and behaviors regarding error reduction in teaching hospitals: a literature review. Academic Medicine 2009;84(12):1765-74.

[10] Najafpour Zh, Gudarzi Z, Keshmiri F, et al. Comparison of education and research indicators of patient safety status between selected hospitals of Tehran university of medical sciences based on WHO standards. Danesh AZ Co. Bimonthly of Education Strategies in Medical Sciences 2014;7(4):241-8. [In Persian]

[11] Raeissi P, Sharifi M, Khosravizadeh O, et al. Survey of cancer patient safety culture: a comparison of chemotherapy and oncology departments of teaching hospitals of Tehran. Asian Pacific Journal of Cancer Prev 2017;18(10):2775-9.

[12] American Hospital Aassociation. Teaching hospitals: their impact on patients and the future health care workforce. Washington (USA): Association of American Medical Colleges, 2009 Sep. 8 p. [Report No.: 202.638.1100.]

[13] Schwartz R, Pogge C. Physician leadership is essential to the survival of teaching hospitals. The American Journal of Surgery 2000;179(6):462-8.

[14] Dehghani M, Haghighi MHH, Tavassoli-Farahi M. Comparing the emergency center information management system of teaching and non-teaching hospitals of Hormozgan University of medical sciences. Modern Information Sciences 2015;1(2):709. [In Persian]

[15] Chase SM, Miller WL, Shaw E, et al. Meeting the challenge of practice quality improvement: a study of seven family medicine residency training practices. Acad Med 2011;86(12):1583-9.

[16] Crespo M, Dridi H. Intensification of universityindustry relationships and its impact on academic research. High Educ 2007;54(1):61-84.

[17] Tien JM, Goldschmidt-Clermont PJ. Healthcare: a complex service system. J Syst Sci Syst Eng 2009;18(3):257-82.

[18] Lack of education and caring space in hospitals, a major problem in teaching hospitals. Apr 252016 [updated 2016 Apr 30; cited 2016 May 2]. http://isna.ir/news/93120301158.

[19] Shirzadi SM, Nasiripour AA, Raeissi P, et al. Hoteling services quality in teaching hospitals of Iran: Model development and Validation. Iran Red Crescent Med J 2017;19(9): e16794. 
[20] Ramanujam R, Rousseau DM. The challenges are organizational not just clinical. J Organiz Behav 2006;27(7):811-27.

[21] Tien JM, Goldschmidt-Clermont PJ. Healthcare: a complex service system. J Syst Sci Syst Eng 2009;18(3):257-82.

[22] Kastor JA. Failure of the merger of the Mount Sinai and New York University hospitals and medical schools: Part 1. Acad Med 2010;85(12):1823-7.

[23] Safarani S, Arab M, Rahimi A, et al. Internal environment analysis of Tehran University of medical sciences hospitals based on wiseboard model. Journal of Payavard Salamat 2012;6(2):101-9.

[24] Ahangar A, Ahmadi AM, Mozayani AH, et al. Key health financing policies with approach risk-sharing to promote health systems in poor and developing countries: Africa and Eastern Mediterranean (WHO) Regions. Iranian Journal of Health Education and Promotion Health 2018.

[25] Haddadi A, Eshrati B, Tavakkoli H, et al. The ways of research promotion in Sina educational-medical hospital. Journal of Arak University of Medical Sciences 2007;10(1):1-13. [In Persian]

[26] Engel KG, Rosenthal M, Sutcliffe KM. Residents' responses to medical error: coping, learning and change. Acad Med 2006;81(1):86-93.

[27] Myers JS, Tess A, Glasheen JJ, et al. The Quality and Safety Educators Academy: fulfilling an unmet need for faculty development. Am J Med Qual 2014;29(1):512.

[28] Kaldjian LC, Jones EW, Wu BJ, et al. Reporting medical errors to improve patient safety: a survey of physicians in teaching hospitals. Arch Intern Med 2008;168(1):40-6.

[29] Levine AS, Detre T, McDonald MC, et al. The relationship between the University of Pittsburgh School of Medicine and the University of Pittsburgh Medical Center-a profile in synergy. Acad Med 2008;83(9):816-26. http://journals.lww.com.

[30] Myers C, Lineen J. Hospital consolidation outlook, surviving in a tough economy. Health Care Financ Manage November, 2009.

[31] Kelley WN. Academic medicine and real health care reform. J Clin Invest 2009;119(10):2852.

[32] Weiss KB, Bagian JP, Nasca TJ. The clinical learning environment: the foundation of graduate medical education. JAMA 2013;309(16):1687-8.

[33] Ahangar A, Ahmadi AM, Mozayani AH, et al. The role of risk-sharing mechanisms in finance health care and towards universal health coverage in low-and middleincome countries of World Health Organization Regions. Journal of Preventive Medicine and Public Health 2018;51(1):59-61.

\section{https://doi.org/10.3961/jpmph.17.199}

[34] Ravangard R, Keshtkaran V, Nicknam SH, et al. The Decision-making styles of managers of public and private hospitals in Shiraz. Hospital Quarterly 2013;12(3):39-45. [In Persian].

[35] Seifer SD, Vranizan K, Grumbach K. Graduate medical education and physician practice location. Implications for physician workforce policy. JAMA 1995;274(9):685-91.
[36] Association of American Medical Colleges. Becoming a new teaching hospital: a guide to the medicare requirements. Washington, DC: Association of American Medical Colleges 2014.

[37] Ahangar A, Ahmadi AM, Mozayani AH, et al. Why are risk-pooling and risk-sharing arrangements necessary for financing healthcare and improving health outcomes in low and lower middle - income countries? Health Journal 2018;10(1):122-31. https://doi.org/10.4236/health Journal. 2018.101010

[38] Levett-Jones $\mathrm{T}$, Lathlean J. Belongingness: a prerequisite for nursing students' clinical learning. Nurse Educ Pract 2008;8(2):103-11.

[39] Safarani S, Arab M, Rahimi A, et al. Internal environment analysis of Tehran University of medical sciences hospitals based on wiseboard model. Journal of Payavard Salamat 2012;6(2):101-9.

[40] Ravaghi H, Rafiei S, Heidarpour P, et al. Facilitators and barriers to implementing clinical governance: a qualitative study among senior managers in Iran. Iranian J Publ Health 2014;43(9):1266-74.

[41] Hafler JP, Ownby AR, Thompson BM, et al. Decoding the learning environment of medical education: a hidden curriculum perspective for faculty development. Acad Med 2011;86(4):440-4.

[42] Valizadeh S, Abedi HA, Zamanzadeh V, et al. The challenges of nursing students in school days: a qualitative study. Iranian Journal of Education 2007;7(2):397-407. [In Persian]

[43] Mohseni M, Seyedin H, Hoseini A, et al. A survey on the responsibility of teaching hospitals of Tehran University of medical sciences. Hospital Journal 2016;14(53):95-100. [In Persian].

[44] Taslimi MS, Zayandeh M. The challenges of creating a hospital performance evaluation system: a review of scientific texts and works. Hakim Research Journal 2012;16(1):35-41.

[45] Geisler BP, Widerberg KF, Berghofer A, et al. Leadership in health care: developing a post-merger strategy for Europe's largest university hospital. Journal of Health Organization and Management 2010;24(3):258-76.

[46] Aij KH, Simons FE, Widdershoven GA, et al. Experiences of leaders in the implementation of Lean in a teaching Hospital-barriers and facilitators in clinical practices: a qualitative study. BMJ Open 2013;3(10):e003605.

[47] Van Rossum TR, Scheele F, Scherpbier AJ, et al. Dealing with the complex dynamics of teaching hospitals. BMC Medical Education 2016;16:104.

[48] Liljedahl M, Björck E, Kalén S, et al. To belong or not to belong: nursing students' interactions with clinical learning environments - an observational study. BMC Medical Education 2016;16:197.

[49] Shirzadi SM, Raeissi P, Nasiripour AA, et al. Factors affecting the quality of hospital hotel services from the patients and their companions' point of view: a national study in Iran. J Res Med Sci 2016;21:46. Published online 2016 Jun 14.

[50] Raeissi P, Sharifi M, Khosravizadeh 0, et al. Survey of Cancer Patient Safety Culture: a comparison of chemotherapy and oncology departments of teaching 
hospitals of Tehran. Asian Pac J Cancer Prev 2017;18(10):2775-9.

[51] Ravaghi H, Mohseni M, Rafiei S, et al. Clinical governance in Iran: theory to practice. Procedia Social and Behavioral Sciences 2014;109:1174-9.

[52] Nasiripour A, Raiessi P, Jafari M. Medical errors disclosure: Is it good or bad? Hosp Pract Res 2018;3(1):16-21.

[53] Ravaghi H, Heidarpour P, Mohseni M, et al. Senior managers' viewpoints toward challenges of implementing clinical governance: a national study in Iran. International Journal of Health Policy and Management 2013;1(4):295-9.

[54] Nuss MA, Robinson B, Buckley PF. A statewide strategy for expanding graduate medical education by establishing new teaching hospitals and residency programs. Academic Medicine 2015;90(9):1264-8.

[55] Ovseiko PV, Melham K, Fowler J, et al. Organizational culture and post-merger integration in an academic health centre: a mixed-methods study. BMC Health Services Research 2015;15:25.

[56] Aljuaid M, Mannan F, Chaudhry Z, et al. Quality of care in university hospitals in Saudi Arabia: a systematic review. BMJ Open 2016;6(2):e008988.

[57] Tess A, Vidyarthi A, Yang J, et al. Bridging the gap: a framework and strategies for integrating the quality and safety mission of teaching hospitals and graduate medical education. Academic Medicine 2015;90(9):1251-7.

[58] Huckman RS, Barro JR. Cohort turnover and productivity: the July phenomenon in teaching hospitals. Massachusetts. National Bureau of Economic Research Mar 2005: p. 45. Report No.: 11182.

[59] Dixon JL, Papaconstantinou HT, Erwin JP 3rd, et al. House Staff Quality Council: One Institution's experience to integrate resident involvement in patient care improvement initiatives. The Ochsner Journal 2013;13(3):394-9.

[60] Thier SO, Kelley WN, Pardes H, et al. Success factors in merging teaching hospitals. Academic Medicine 2014;89(2):219-23.

[61] Trotta A, Cardamone E, Cavallaro G, et al. Applying the balanced scorecard approach in teaching hospitals: a literature review and conceptual framework. Int J Health Plann Mgmt 2013;28(2):181-201.
[62] Souba W, Notestine M, Way D, et al. Do deans and teaching hospital CEOs agree on what it takes to be a successful clinical department chair? Academic Medicine 2011;86(8):974-81.

[63] De Castro LMS, Pereira MEL, Da Silva ACM, et al. Assessment of teaching - health care integration and performance in university hospitals. Performance and integration between teaching and healthcare. Rev Saude Publica 2010;44(4):581-90. http://dx.doi.org/10.1590/S003489102010000400001

[64] Omar M, Gerein N, Tarin E, et al. Training evaluation: a case study of training Iranian health managers. Human Resources for Health 2009;7:20. https://doi.org/10.1186/1478-4491-7-20

[65] Flanders S, Centor B, Weber V, et al. Challenges and opportunities in academic hospital medicine: report from the academic hospital medicine summit. J Gen Intern Med 2009;24(5):636-41.

[66] Ramanujam R, Rousseau DM. The challenges are organizational not just clinical. J Organiz Behav 2006;27(7):811-27.

[67] Kane RL, Bershadsky B, Weinert C, et al. Estimating the patient care costs of teaching in a teaching hospital The American Journal of Medicine 2005;118(7):76772.

[68] Ayanian JZ, Weissman JS. Teaching hospital and quality of care: a review of the literature. Harvard Medical School. The Milbank Quarterly 2002;80(3):569-93.

[69] Haghparast H. Estimate the production functions in hospitals of Iran University of medical sciences during 1992-2002 [PhD thesis]. Tehran: Iran University of medical sciences, school of health management and medical information science, 2003. [In Persian]

[70] Mirmoghtadaei Z, Rokh-Afruz D, Salarianzadeh MH. A review of the challenges of the integration of medical education with the Iran Service Delivery System from the perspective of human capital. Management of Health Care 2015;6(2):7-15. [In Persian]. 